\section{An IKKo-E2F1-BMI1 cascade activated by infiltrating $B$ cells controls prostate regeneration and tumor recurrence}

\author{
Massimo Ammirante, ,,3 Ali I. Kuraishy, ,,3 \\ Shabnam Shalapour, ${ }^{1}$ Amy Strasner, ${ }^{1}$ \\ Claudia Ramirez-Sanchez, ${ }^{1}$ Weizhou Zhang, ${ }^{1}$ \\ Ahmed Shabaik, ${ }^{2}$ and Michael Karin ${ }^{1,2,4}$ \\ ${ }^{1}$ Laboratory of Gene Regulation and Signal Transduction, \\ Department of Pharmacology, ${ }^{2}$ Department of Pathology, \\ School of Medicine, University of California at San Diego, \\ La Jolla, California 92093, USA
}

Androgen-deprived prostate cancer (PCa) is infiltrated by B lymphocytes that produce cytokines that activate IKB kinase $\alpha(I K K \alpha)$ to accelerate the emergence of castrationresistant tumors. We now demonstrate that infiltrating $B$ lymphocytes and IKK $\alpha$ are also required for androgendependent expansion of epithelial progenitors responsible for prostate regeneration. In these cells and in PCa cells, IKK $\alpha$ phosphorylates transcription factor E2F1 on a site that promotes its nuclear translocation, association with the coactivator $C B P$, and recruitment to critical genomic targets that include Bmi1, a key regulator of normal and cancerous prostate stem cell renewal. The IKK $\alpha-B M I 1$ pathway is also activated in human PCa.

Supplemental material is available for this article.

Received April 17, 2013; revised version accepted May 24, 2013.

Tissue injury triggers an inflammatory response that promotes clearance of dead cells and activates a regenerative wound healing process (Velnar et al. 2009). While the role of damage-associated molecular patterns (DAMPs) in the activation of injury-induced inflammation is well established (Zitvogel et al. 2010), the molecular mechanisms through which the consequent inflammatory response promotes regeneration remain nebulous. In addition to its role in tissue regeneration, the inflammatory response triggered by tissue injury is likely to play a key role in tumorigenesis, and several malignancies are induced as a consequence of chronic tissue damage (Kuraishy et al. 2011). Indeed, tumors were pointed out to be analogous to wounds that do not heal (Dvorak 1986). Furthermore, signaling pathways that promote tissue regeneration and stem cell renewal or expansion of transient amplifying cells, the Wnt and Hedgehog pathways, were also found

[Keywords: B cells; prostate; regeneration]

${ }^{3}$ These authors contributed equally to this work.

${ }^{4}$ Corresponding author

E-mail karinoffice@ucsd.edu

Article published online ahead of print. Article and publication date are online at http://www.genesdev.org/cgi/doi/10.1101/gad.220202.113. Freely available online through the Genes \& Development Open Access option. to be key players in tumorigenesis (Beachy et al. 2004). However, it is unknown which regenerative pathways are activated in response to inflammatory signals generated by tissue injury. It is also not clear how tissue injury leads to stem cell activation or expansion of transient amplifying cells in both normal tissues and malignant tumors.

The NF-кB signaling pathway is involved in inflammation, tissue repair, and cancer (Ben-Neriah and Karin 2011). To study roles of NF-кB in cancer, we focused on the IкB kinase $\alpha(\mathrm{IKK} \alpha)$ and IKK $\beta$ catalytic subunits (Karin 2009). While both kinases can activate NF-кB-mediated transcription, IKK $\alpha$ also has NF-кB-independent functions in development (Hu et al. 2001) and tumorigenesis (Luo et al. 2007; Ammirante et al. 2010). The NF-кB-independent activities of IKK $\alpha$ are evident in prostate cancer (PCa), the most common nonskin cancer in men. PCa accounts for $>32,000$ deaths each year in the United States, making it the second leading cause of cancer deaths in men (Siegel et al. 2012). This is due to the fact that while androgen ablation or chemical castration is effective in the short term, the cancer will inevitably switch to a more aggressive and metastatic form, termed castration-resistant $\mathrm{PCa}$ (CRPC) (Gulley et al. 2003). The genesis of CRPC depends on the emergence of $\mathrm{PCa}$ stem/progenitor cells that either do not require androgen signaling for growth and survival or are highly sensitive to castrate levels of androgens (Maitland and Collins 2008). Using mouse models, we found that androgen ablation causes infiltration of the regressing tumors with lymphocytes that produce cytokines, which activate IKK $\alpha$ in surviving PCa cells, thereby accelerating CRPC emergence (Ammirante et al. 2010). Among the infiltrating cells, B cells are of particular importance, as they produce lymphotoxin (LT), a heterotrimeric member of the TNF family that activates IKK $\alpha$ (Ammirante et al. 2010). Ablation of B cells or inhibition of their recruitment into the regressing tumors prevents IKK $\alpha$ activation and delays CRPC regrowth. LT signaling leads to nuclear accumulation of IKK $\alpha$ and stimulates metastatic spread in a mouse model of PCa with neuroendocrine characteristics (Luo et al. 2007). However, the molecular mechanisms by which nuclear IKK $\alpha$ enhances survival and proliferation of cells that give rise to metastases and CRPC are not clear. Previous studies suggested that nuclear IKK $\alpha$ acts as a histone H3 kinase (Yamamoto et al. 2003), whereas other reports have described an interaction between IKK $\alpha$ and the histone acetylase (HAT) $\mathrm{CBP} / \mathrm{p} 300$ that results in phosphorylation of the latter (Huang et al. 2007). IKK $\alpha$ was also reported to regulate the expression and activity of transcription factor E2F1 (Tu et al. 2006) and counteract SMRT repressor activity leading to acetylation of p65/RelA by p300 (Hoberg et al. 2006).

Here we asked whether IKK $\alpha$ activation by inflammatory signals is also of importance in androgen-induced regeneration of the normal, nonneoplastic prostate. Androgeninduced prostate regeneration is thought to be mediated through activation of adult tissue progenitor/stem cells that remain after involution (English et al. 1987). Presumably, these progenitors are induced to proliferate in a cell-autonomous manner upon androgen receptor (AR) activation (English et al. 1987). We now show that androgeninduced prostate regeneration is also dependent on a noncell-autonomous mechanism mediated by B lymphocytes that activate IKK $\alpha$ within tissue progenitors. The 
same mechanism may account for the recurrence of PCa after androgen ablation. In both cases, IKK $\alpha$ operates by inducing the phosphorylation and nuclear translocation of E2F1 to promote its recruitment to the promoters/regulatory regions of the Bmil and Ccne genes, which encode positive regulators of progenitor cell proliferation.

\section{Results and Discussion}

To study the mechanisms underlying androgen-induced prostate regeneration, we used castration to deprive mice of androgen and reduce prostate weight by $>90 \%$ within 1 wk (Supplemental Fig. S1A). As shown before (Karhadkar et al. 2004), subcutaneous injection of testosterone (described hereafter as androgen supplementation) every $4 \mathrm{~d}$ fully restored prostate weight and structure (Supplemental Fig. S1B,C). To delineate the role of inflammatory signaling in androgen supplementation-induced prostate regeneration, we performed the same experiment in $I k k \alpha^{A A / A A}$ mutant mice in which activation loop serines, whose phosphorylation is needed for IKK $\alpha$ activation, were replaced with alanines (Cao et al. 2001). IKK $\alpha$ responds to extracellular inflammatory signals by translocating to the nucleus, and this process is critical for CRPC emergence (Ammirante et al. 2010). Ikk $\alpha^{+/ A A}$ and $I k k \alpha^{\mathrm{AA} / \mathrm{AA}}$ mice exhibited similar prostate weight and structure before castration (Supplemental Fig. S1D). However, unlike $I k k \alpha^{+/ \mathrm{AA}}$ mice, $I k k \alpha^{\mathrm{AA} / \mathrm{AA}}$ mice failed to regenerate their prostates after androgen supplementation (Fig. 1A). Interestingly, immunohistochemistry (IHC) revealed a more than fourfold increase in nuclear IKK $\alpha$ after castration and androgen supplementation in wild-type mice (Fig. 1B). In PCa cells, IKK $\alpha$ activation and nuclear translocation are controlled by LT $\alpha$ : $\beta$ heterotrimers produced by infiltrating B cells (Supplemental Fig S2) that are recruited upon castration-induced tumor shrinkage (Ammirante et al. 2010). Indeed, immunofluorescence (IF) revealed infiltration of $B$ cells surrounding the regenerating prostate lobe after castration and androgen supplementation (Fig. 1C), and quantitative RT-PCR (qRT-PCR) revealed increased expression of genes encoding LT $\alpha$ and LT $\beta$ subunits in prostates of castrated and androgensupplemented mice (Fig. 1D). B-cell infiltration, LT induction, and IKK $\alpha$ dependence of prostate regeneration were also observed upon daily supplementation of castrated mice with a different androgen-dihydrotestosterone (DHT), indicating that this phenomenon is not procedure-specific (Supplemental Fig. S3A-C). As seen in the previous experiments, the prostate weight in the Ikk $\alpha^{A A / A A}$ mutant was significantly lower than in heterozygous control mice (Supplemental Fig. S3B). Furthermore LT $\alpha$ and LT $\beta$ production was increased in regenerated prostates (Supplemental Fig. S3C). The presence of B cells within the regenerated prostate was specific, as it was not detected in $R a g 1^{-/-}$mice (which lack both $\mathrm{B}$ and $\mathrm{T}$ cells) unless they were reconstituted with splenic B cells (Supplemental Fig. S3D). These results indicate that, as seen in $\mathrm{PCa}$, after castration and androgen supplementation, the infiltration of inflammatory cells into the involuting prostate results in IKK $\alpha$ nuclear translocation. This process may be important for androgen-induced regeneration.

To examine the role of infiltrating lymphocytes in androgen-induced prostate regeneration, we subjected $J_{H}^{-/-}$and $C d 4^{-1-}$ mice, which lack either B or $\mathrm{CD} 4^{+}$ T cells, respectively (Rahemtulla et al. 1991; Chen et al. 1993), to the castration regeneration experiment described
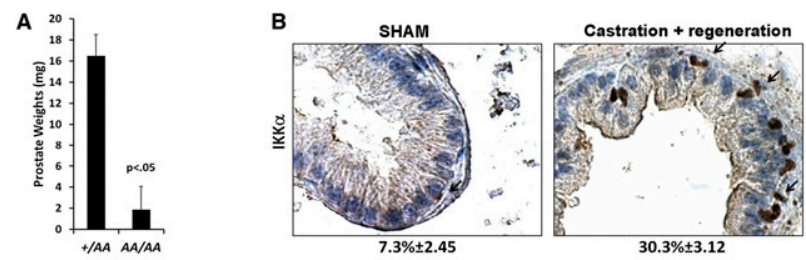

C

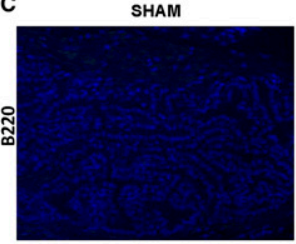

Castration + regeneration
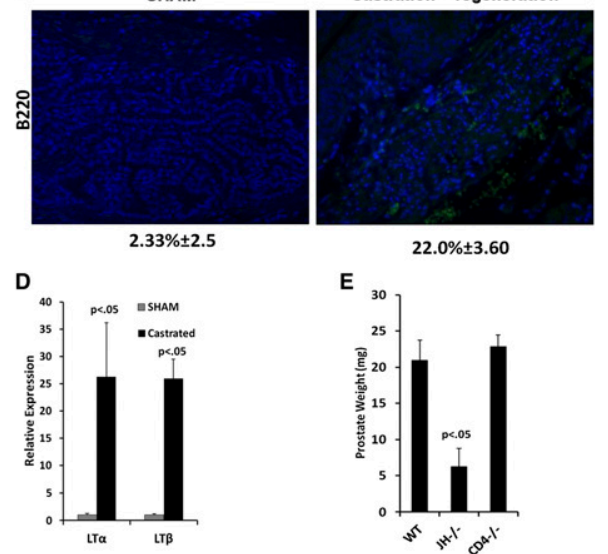

E

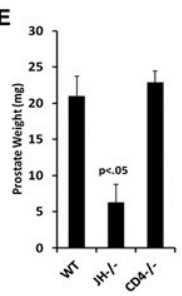

Figure 1. B cells and IKK $\alpha$ control prostate regeneration. (A) Prostates of $I k k \alpha^{+/ A A}$ and $I k k \alpha^{A A / A A}$ mice were weighed $17 \mathrm{~d}$ after castration and androgen replacement. $(B)$ Prostates of sham-operated or castrated wild-type (WT) mice were collected and analyzed by IHC for IKK $\alpha$ nuclear translocation. Magnification, $400 \times$. Percentages of cells displaying nuclear IKK $\alpha$ are indicated below each panel. $n=3$. (C) Prostates of wild-type mice were collected after sham operation or castration and regeneration and analyzed by IF for $\mathrm{B} 220^{+}$cell infiltration. Magnification, $400 \times$. Percentages of $\mathrm{B} 22 \mathrm{O}^{+}$cells are indicated below each panel. $n=3$. (D) RNAs extracted from prostates of wildtype mice $17 \mathrm{~d}$ after sham operation or castration and subsequent androgen replacement were analyzed for $L T \alpha$ and $L T \beta$ expression. (E) Prostates of wild-type, $J_{H}^{-/-}$, or $\mathrm{Cd}^{-/-}$mice were weighed $17 \mathrm{~d}$ after castration and androgen replacement. In all panels, the values represent mean $\pm \mathrm{SD} ; n=3$.

above. The B-cell, but not the $\mathrm{CD}^{+}{ }^{+} \mathrm{T}$-cell, deficiency abrogated androgen-induced prostate regrowth (Fig. 1E). Furthermore, $R a g 1^{-/-}$mice, which lack both B and T cells, were also defective in androgen-induced prostate regeneration, but their reconstitution with splenic B cells derived from either wild-type or $I k k \alpha{ }^{\mathrm{AA} / \mathrm{AA}}$ mice restored regeneration (Supplemental Fig. S4A) and expression of LT $\beta$ (Supplemental Fig. S4B) as well as the presence of B cells within the regenerating prostate (Supplemental Fig. S3D), thus confirming that B cells rather than T cells are needed for androgen-induced prostate regeneration. $I_{H}{ }^{-/-}$male mice exhibited fully normal prostates prior to castration (Supplemental Fig. S1D) and did not exhibit any reproductive abnormalities, indicating that this phenotype is not due to a defect in initial prostate development,. Prostate epithelial cells expressed LT $\beta R$ but hardly any receptor activator of NF-кB (RANK) (Supplemental Fig. S5A,B), thus explaining why the RANK ligand, which can also activate IKK $\alpha$ (Luo et al. 2007) and whose expression is also induced upon castration but is not affected by B-cell depletion (data not shown), cannot substitute for LT $\alpha$ : $\beta$. Notably, LT $\alpha$, whose expression is not reduced after B-cell ablation (Supplemental Fig. S4B; Ammirante et al. 2010), cannot bind to LT $\beta R$ in the absence of LT $\beta$. We therefore postulate that the effect of B cells on the regenerating normal prostate may also be mediated via LT $\alpha$ : $\beta$ heterotrimers, 
as demonstrated for CRPC development (Ammirante et al. 2010).

We hypothesized that defective prostate regrowth in $I k k \alpha^{A A / A A}$ mice correlated with diminished expansion of prostate epithelial progenitors that are responsible for androgen-induced regeneration and can form protospheres in culture (English et al. 1987; Karhadkar et al. 2004). Indeed, the prostate rudiments of castrated androgensupplemented $I k k \alpha^{\mathrm{AA} / \mathrm{AA}}$ mice contained much lower numbers of protosphere-forming units (Fig. 2A). To further support our hypothesis, we examined expression of two markers of prostate progenitor cells: p63 and BMI1 (Lukacs et al. 2010). IHC of regenerating wild-type prostates revealed a substantial increase in cells expressing p63 and BMI1 (Fig. 2B,C). Furthermore, nuclear translocation of IKK $\alpha$ was observed in both $\mathrm{p} 3^{+}$and $\mathrm{BMII}^{+}$cells in the regenerating prostates (Supplemental Fig. S6A,B), and IF analysis revealed colocalization of IKK $\alpha$ and BMI in nuclei within the regenerating prostate (Fig. 2D). Bmi1 mRNA also increased after castration and androgen sup-
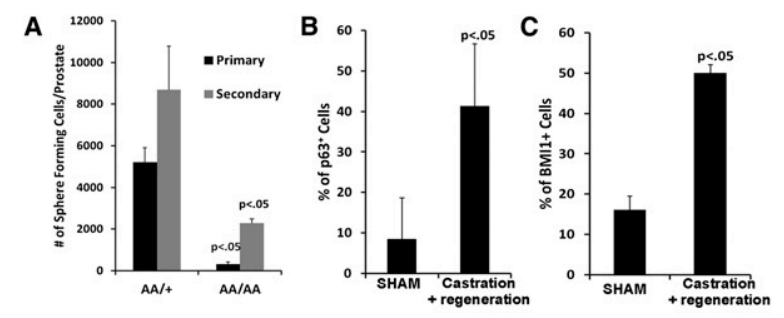

D

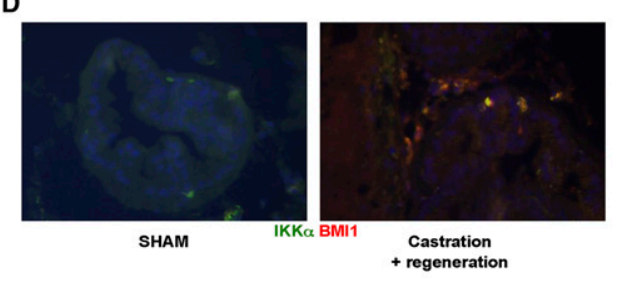

E
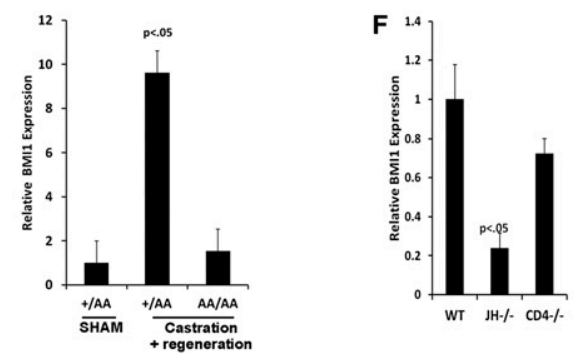

Figure 2. IKK $\alpha$ and $\mathrm{B}$ cells control prostate and $\mathrm{PCa}$ epithelial progenitor proliferation. (A) Single-cell suspensions of $I \mathrm{kk} \alpha^{+/ A A}$ and $I k k \alpha A A / A A$ prostates $17 \mathrm{~d}$ after castration and androgen replacement were analyzed for sphere-forming ability. After $10 \mathrm{~d}$, the spheres were dissociated, and equal numbers of cells were replated for secondary sphere formation. The number of sphere-forming cells per prostate was calculated by normalizing the observed number of primary and secondary spheres to the total amount of epithelial cells harvested from each prostate. $(B, C)$ Prostates of wild-type $(\mathrm{WT})$ mice collected $17 \mathrm{~d}$ after sham operation or castration and subsequent androgen replacement were analyzed by $\mathrm{IHC}$ for p63 $(B)$ or BMI1 $(C)$ expression. Percentages of $\mathrm{p} 3^{+}$and $\mathrm{BMI}^{+}$cells were determined. $n=3$. (D) Sham-operated and regenerated prostates of wild-type mice were analyzed by IF for IKK $\alpha$ (green) and BMI1 (red). Magnification, $200 \times$. $(E, F)$ RNAs extracted from prostates of the indicated genotypes prepared as above were analyzed for Bmil mRNA by qRTPCR. In all panels, the values represent mean $\pm \mathrm{SD} ; n=3$. plementation in an IKK $\alpha$-dependent and B-cell-dependent manner (Fig. 2E,F). Furthermore, B-cell reconstitution of Rag1 $^{-/-}$mice restored Bmi1 mRNA induction in the regenerating prostates (Supplemental Fig. S4B). Expression of two other putative prostate progenitor cell markers, Sox2 and $C d 133$ (Kasper 2008), was also higher in $I k k \alpha^{+/ A A}$ mice than in Ikk $\alpha^{A A / A A}$ mice (Supplemental Fig. S6C). These results implicate IKK $\alpha$ in the proliferation of prostate epithelial progenitors in response to castration and androgen supplementation. We also found that IKK $\alpha$ and B cells were required for induction of $\mathrm{CD} 45^{-} \mathrm{CD} 49 \mathrm{f}^{+} \mathrm{Sca} 1^{+}$cells within the regenerating prostate (Supplemental Fig. S6D,E). CD49f and Scal are thought to be selective markers of murine prostate stem cells (Lawson et al. 2007).

If IKK $\alpha$ controls expansion of prostate epithelial progenitors, it may have a similar effect on PCa progenitors, which presumably account for CRPC development (Maitland and Collins 2008). Indeed, analysis of subcutaneous tumors formed by androgen-dependent myc-CaP cells at 2 wk after castration revealed that castration increased the tumoral content of $\mathrm{p}^{+} 3^{+}$cells and Sox2, Nanog, and Cd133 mRNAs and that all of these increases were IKK $\alpha$-dependent (Supplemental Fig. S7A-C). CD133 ${ }^{+}$ cells from myc-CaP tumors displayed nuclear IKK $\alpha$ (Supplemental Fig. S7D), and the castration-induced increase in their frequency was inhibited by IKK $\alpha$ silencing but rescued by ectopic BMI1 expression at $1 \mathrm{wk}$ after castration (when tumors formed by IKK $\alpha$-positive and IKK $\alpha$-silenced cells were similar in size) (Supplemental Fig. S7E,F). TRAMP mice in which PCa development is induced by SV40 $\mathrm{T}$ antigen also develop CRPC after castration (Greenberg et al. 1995). Homozygosity for the Ikk $\alpha^{\mathrm{AA}}$ allele modestly retarded primary tumor growth (Supplemental Fig. S8A) but completely prevented CRPC emergence in castrated TRAMP mice (Fig. 3A; Supplemental Fig. S8B). Carcinoma cells of CRPC in $I k k \alpha^{+/ A A} /$ TRAMP mice exhibited IKK $\alpha$ nuclear translocation (Supplemental Fig. S8C), and tumoral expression of BMI1 was IKK $\alpha$ dependent (Fig. 3B; Supplemental Fig. S8D,E). A strong correlation between nuclear IKK $\alpha$ and high BMI1 expression was also seen in human PCa (Fig. 3C). These data suggest that nuclear IKK $\alpha$ controls CRPC development through expansion of $\mathrm{BMII}^{+}$progenitors and that it may have a similar role in human PCa.

As IKK $\alpha$ nuclear translocation correlated with BMI expression in both normal and transformed prostate epithelial cells, we asked whether nuclear IKK $\alpha$ directly regulated Bmil transcription. Bmil mRNA expression increased in myc-CaP cells during CRPC formation in an IKK $\alpha$-dependent manner (Supplemental Fig. S9A-C). LT sequestration with an LT $\beta$ R-Fc fusion protein inhibited Bmi1 mRNA expression in myc-CaP tumors of castrated mice (Supplemental Fig. S9D). Transduction of human and mouse $\mathrm{PCa}$ cell lines with lentiviruses encoding constitutively active HA-tagged IKK $\alpha(\mathrm{EE})$, but not with inactivatable IKK $\alpha(\mathrm{AA})$ or nuclear transport-defective IKK $\alpha(E E-N L S)$ (Sil et al. 2004), enhanced Bmi1 expression (Supplemental Fig. S10A,B), supporting a direct involvement of IKK $\alpha$ in control of Bmi1 transcription. Chromatin immunoprecipitation (ChIP) analysis of these cells revealed an association between $\mathrm{IKK} \alpha(\mathrm{EE})$ and the $B \mathrm{mi1}$ promoter (Fig. 3D). Similarly, ChIP analysis of CRPC tumor samples revealed an association between endogenous IKK $\alpha$ and the Bmi1 promoter (Supplemental Fig. S10C,D). Binding of IKK $\alpha$ to the Bmil promoter was specific, as it 
A

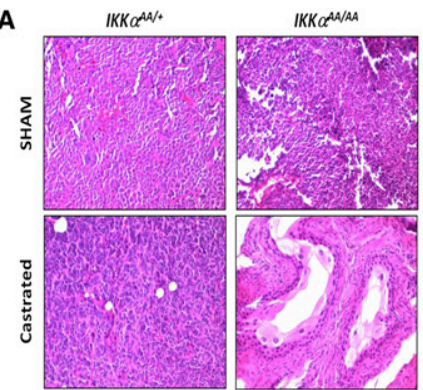

C

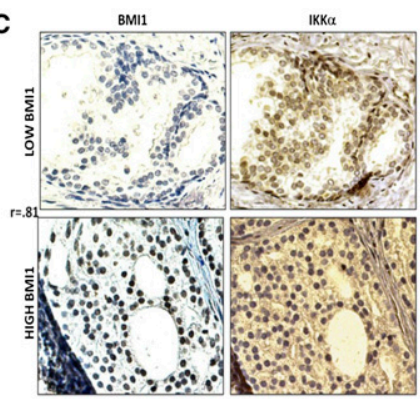

E

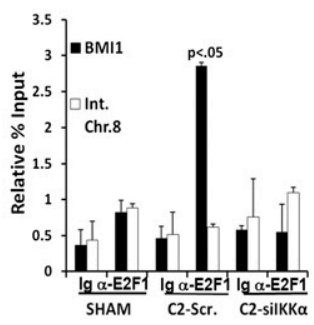

B

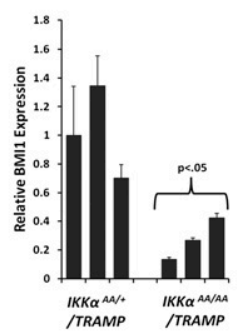

D

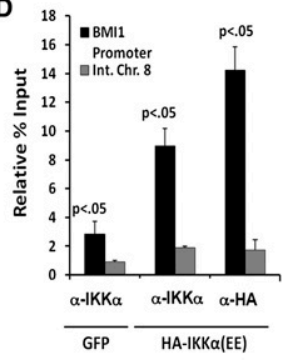

F

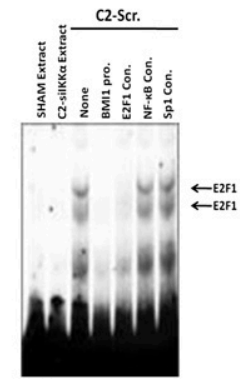

Figure 3. IKK $\alpha$ stimulates E2F1-mediated Bmil gene induction. $(A)$ Histological analysis (H\&E staining of paraffin-embedded sections; magnification, $100 \times$ ) of prostates from 24 -wk-old $I k k \alpha^{+/ A A} /$ TRAMP and $I k k \alpha^{A A / A A} /$ TRAMP mice that were castrated or sham-operated at $12 \mathrm{wk}$ of age. $(B)$ Prostates of 24 -wk-old mice of the indicated genotypes castrated at 12 wk of age were analyzed for Bmi1 mRNA expression by qRT-PCR. $(C)$ Serial sections of paraffin-embedded human PCa tissues were analyzed for nuclear IKK $\alpha$ and BMI1 by IHC. Nuclear staining indices were quantitated, and the correlation coefficient is indicated at the left. Magnification, $400 \times$. (D) ChIP analysis of IKK $\alpha$ recruitment to the Bmil promoter. Cross-linked and sheared chromatin from myc-CaP cells stably infected with GFP or IKK $\alpha(\mathrm{EE})$ lentiviruses was immunoprecipitated with IKK $\alpha$ or HA antibodies and analyzed by qPCR with primers to the Bmil promoter or an intergenic region of chromosome 8 . The percentage input was calculated by determining the ratio of immunoprecipitated DNA with each antibody to a $10 \%$ input sample. (E) Chromatin was isolated from myc-CaP tumors established by mock-silenced (Scr.) or IKK $\alpha$-silenced cells 2 wk after sham operation or castration. After cross-linking and shearing, chromatin was immunoprecipitated with antibodies to E2F1 or control IgG, and the content of Bmi1 promoter DNA was determined as above. $(F)$ Nuclear extracts were prepared from the myc-CaP tumors described above, and E2F1 DNA-binding activity was analyzed by EMSA with the Bmi1 E2F1binding site. For competition experiments, 100-fold excess of nonradioactive competitor oligonucleotides representing the Bmi1 E2F1 site or consensus binding sites of the indicated transcription factors were added to the reactions $10 \mathrm{~min}$ before probe addition. In $B, D$, and $E$ the values represent mean $\pm \mathrm{SD} n=3$.

was not detected in cells with silenced IKK $\alpha$ expression (Supplemental Fig. S10D). As IKK $\alpha$ has no recognizable DNA-binding domain, we searched for a sequence-specific

transcription factor that may recruit the kinase to the Bmi1 promoter. While ChIP experiments ruled out involvement of NF-кB RelA or RelB proteins (Supplemental Fig. S11A), similar experiments demonstrated IKK $\alpha$-dependent recruitment of E2F1 to the Bmi1 promoter (Fig. 3E). Direct control of Bmi1 transcription by E2F1 has been reported previously (Tu et al. 2006). IKK $\alpha$-dependent E2F1 binding to the Bmi1 promoter was not due to effects of IKK $\alpha$ on E2F1 expression or c-Myc recruitment to the Bmi1 promoter (Supplemental Fig. S11B,C; Guo et al. 2007). Electrophoretic mobility shift assays (EMSAs) confirmed IKK $\alpha$-dependent binding of E2F1 to a DNA sequence from the Bmi1 promoter (Fig. $3 \mathrm{~F}$ ), and UV cross-linking experiments revealed that E2F1 bound this sequence much stronger than IKK $\alpha$ (Supplemental Fig. S11D).

We examined how IKK $\alpha$ may control E2F1 chromatin recruitment. In vitro, IKK $\alpha$ phosphorylated E2F1 at Ser403 (Supplemental Fig. S11E), a previously reported E2F1 phosphorylation site (Ivanova et al. 2009). A phosphomimetic Ser403-to-Glu403 substitution promoted E2F1 nuclear localization (Fig. 4A), and after castration, E2F1 translocated to nuclei of prostate epithelial and PCa cells in an IKK $\alpha$-dependent manner (Fig. 4B,C), thus explaining how IKK $\alpha$ enhances E2F1 recruitment to the Bmi1 promoter. Castration also increased the nuclear abundance of phosphorylated (phospho-T433) E2F1 in PCa cells (Supplemental Fig. S11F). Activated IKK $\alpha$ also supported an interaction between E2F1 and CBP (Supplemental Fig. S11G), while it interacted with E2F1 (Supplemental Fig. S11H). $\mathrm{CBP}$ is a histone $\mathrm{H} 3$ acetyltransferase (Iyer et al. 2004), and castration of tumor-bearing mice led to IKK $\alpha$-dependent $\mathrm{H} 3$ acetylation and CBP recruitment (Fig. 4D,E) to the $B m i 1$ promoter in Myc-CaP cells. This suggests that IKK $\alpha$ may further regulate E2F1 activity via CBP, which can acetylate E2F1 to increase its stability and DNA binding (Trouche and Kouzarides 1996; Ianari et al. 2004) and is recruited to certain promoters in an IKK $\alpha$-dependent manner (Hoberg et al. 2006; Huang et al. 2007). In support of this interpretation, ectopic E2F1 expression in Myc-CaP cells increased Bmil expression in an IKK $\alpha$-dependent manner (Supplemental Fig. S12A). Functional cooperation between IKK $\alpha$ and E2F1 was also observed at the Ccne (cyclin E) gene, a well-documented E2F1 target (Supplemental Fig. S12B,C; Ohtani et al. 1995). Taken together, these results suggest that E2F1 is phosphorylated by IKK $\alpha$ in order to enhance E2F1 nuclear localization. This results in E2F1-mediated recruitment of CBP to the Bmi1 promoter, thus enhancing Bmil transcription.

We next examined the functional role of IKK $\alpha$-induced Bmil expression in PCa. BMI1 depletion with siRNA underscored its importance for growth of myc-CaP tumors, as BMI1 silencing in Myc-CaP cells reduced tumor growth, and the few tumors that grew after 4 wk displayed BMI1 expression, suggesting that they were derived from cells that escaped BMI1 silencing (Supplemental Fig. S13A,B). Conversely, ectopic BMI1 expression in myc-CaP cells whose IKK $\alpha$ was siRNA-silenced strongly enhanced tumor regrowth in castrated mice (Fig. 5A; Supplemental Fig. S13C). Curiously, 3 wk after castration, IKK $\alpha$-silenced myc-CaP cells had regained BMIl expression (Fig. $5 \mathrm{~B}$ ), thus explaining the temporary nature of delayed tumor regrowth caused by IKK $\alpha$ silencing in these very aggressive cells. BMI1 was proposed to promote cell proliferation and inhibit senescence through epigenetic silencing of the $p 16^{\text {Ink4a }} / p 19^{\text {Arf }}$ locus (Jacobs et al. 1999). Congruently, 
A

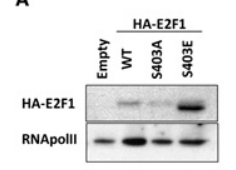

C

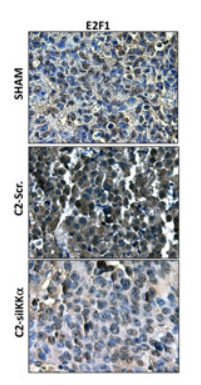

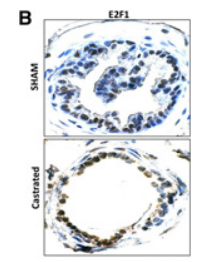

D

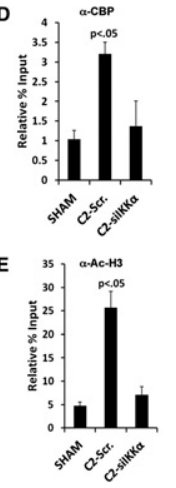

Figure 4. IKK $\alpha$ phosphorylates $\mathrm{BM} 1$ and controls its nuclear translocation. (A) HEK293T cells were transfected with vectors expressing wild-type (WT) E2F1 or mutants in which the IKK $\alpha$ phosphorylation site was replaced with alanine (A) or glutamate (E) residues. After $48 \mathrm{~h}$, nuclear extracts were prepared and analyzed by immunoblotting. $(B)$ Prostates of wild-type mice were collected after sham operation or castration and androgen replacement and analyzed by IHC for E2F1 $\alpha$. Magnification, 400×. (C) Subcutaneous myc-CaP bearing mock-silenced (Scr.) or IKK $\alpha$-silenced tumors were collected 2 wk after castration or sham operation and analyzed by IHC for E2F1. Magnification, $400 \times$. $(D, E)$ Chromatin isolated from subcutaneous myc-CaP tumors formed by mock-silenced (Scr.) or IKK $\alpha$-silenced cells 2 wk after sham operation or castration was subjected to ChIP analysis with antibodies to $\mathrm{CBP}(D)$ or Ac-H3 $(E)$. Relative percentage input was determined as above. In $D$ and $E$, the values represent mean \pm SD; $n=3$.

tumors formed by IKK $\alpha$-silenced Myc-CaP cells or those that grew in the absence of LT signaling exhibited elevated p16 and p19 expression, which was reduced by ectopic BMIl (Fig. 5C; Supplemental Fig. S13D). ChIP experiments indicated that castration increased the recruitment of BMI1 to multiple sites at the Ink4a/Arf locus (Fig. 5D; Supplemental Fig. S13E). BMI1 and other PRC1 components suppress Ink4a/Arf transcription through direct binding and H2A ubiquitination (Wang et al. 2004), a chromatin mark whose presence at the Ink4a/Arf locus increased after castration in an IKK $\alpha$-dependent manner (Supplemental Fig. S13F). There was also a significant, IKK $\alpha$-dependent increase in global ubiquitinated $\mathrm{H} 2 \mathrm{~A}$ (ubi-H2A) within PCa cells after castration in both myc-CaP and TRAMP tumors (Fig. 5E,F). We also found significantly elevated BMIl and ubi-H2A staining in human PCa specimens relative to normal prostatic tissue or benign prostatic hyperplasia (Fig. 5G,H) as well as a strong correlation coefficient of 0.94 between BMI1 and ubi-H2A staining of these samples. These results suggest that IKK $\alpha$-induced Bmi1 expression is a critical factor in promoting $\mathrm{PCa}$ proliferation, possibly through suppression of the Ink4a/ Arf locus.

Tissue injury and subsequent inflammation can promote tumorigenesis by activating a regenerative response (Beachy et al. 2004; Kuraishy et al. 2011). However, how injury-triggered inflammation controls regeneration has

not been clear. We now show that androgen-induced regrowth of the involuted prostate is not an entirely cellautonomous process as previously assumed, as it is highly dependent on activation of IKK $\alpha$ in prostate tissue progenitors in response to a signal provided by B cells that infiltrate the androgen-deprived prostate. This signal is likely to be LT $\alpha: \beta$ heterotrimers, which bind to LT $\beta$ R (Ammirante et al. 2010). Most likely, the trigger for B-cell infiltration in both cases is tissue injury or cancer cell death, which generates signals that lead to induction of CXCL13, a B-cell chemoattractant (Ammirante et al. 2010). The one difference between androgen-induced prostate regeneration and recurrence of CRPC is their dependence on androgens. Whereas regeneration of the normal prostate does not occur in the absence of androgen supplementation, the residual amount of androgens present in castrated mice is sufficient for driving the growth of CRPC as long as IKK $\alpha$ is activated. Our results demonstrate that the IKK $\alpha-$ BMIl axis is also activated in human $\mathrm{PCa}$ and suggest that its pharmacological inhibition in combination with androgen ablation can prevent CRPC emergence. Notably, neither IKK $\alpha$ inhibition nor androgen ablation alone can completely block prostate tumor growth in TRAMP mice. However, mice that have been subjected to both castration and IKK $\alpha$ inhibition (at least genetically) do not display any recurrent tumors for at least several months after androgen ablation. Thus, IKK $\alpha$ inhibition

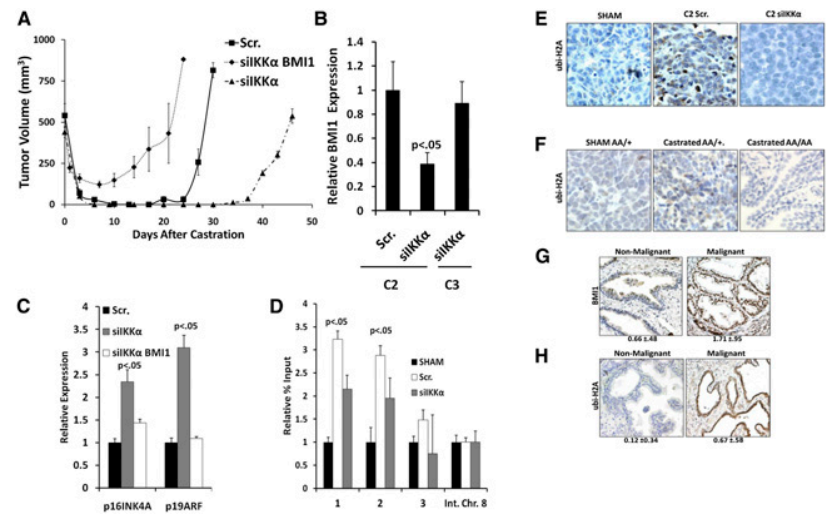

Figure 5. BMIl controls castration-resistant tumor growth. $(A)$ myc-CaP tumors were established in wild-type (WT) mice with cells subjected to mock silencing (Scr.), IKK $\alpha$ silencing, or IKK $\alpha$ silencing + ectopic BMI1 expression. When tumors reached $500 \mathrm{~mm}^{3}$, mice were castrated, and tumor volume was measured. (B) RNA from subcutaneous myc-CaP tumors formed by mock-silenced (Scr.) or IKK $\alpha$-silenced cells was collected 2 or 3 wk after castration and analyzed for Bmi1 expression. $(C)$ RNAs from subcutaneous myc$\mathrm{CaP}$ tumors formed by the cells in $A$ were analyzed for $p 16$ and $p 19$ expression $2 \mathrm{wk}$ after castration. (D) Chromatin from subcutaneous myc-CaP tumors formed by mock-silenced (Scr.) or IKK $\alpha$-silenced cells collected $2 \mathrm{wk}$ after castration or sham operation was subjected to ChIP analysis using antibodies to BMIl or control Ig. The presence of Ink 4a/Arf sequences was examined by PCR using the primers in Supplemental Figure S13E or the intergenic region from chromosome 8. (E) Subcutaneous myc-CaP tumors formed as in $A$ were analyzed by IHC for ubi-H2A content. (F) Prostates of $I k k \alpha^{+/ A A} /$ TRAMP and $I k k \alpha^{A A / A A} /$ TRAMP mice were collected $12 \mathrm{wk}$ after sham operation or castration and stained for ubi-H2A. $(G, H)$ Paraffin-embedded human prostate sections representing nonmalignant tissue $(n=17)$ and PCa $(n=13)$ were stained for BMI1 $(G)$ or ubi-H2A $(H)$. The staining indices are indicated at the bottom. $P<0.01$ for the malignant samples. Magnification, $400 \times$ for all images. In $A-D$, the values represent mean $\pm \mathrm{SD} ; n=3$. 
appears to exert a synthetic lethal effect when combined with androgen ablation.

\section{Materials and methods}

In brief, mice were handled according to institutional and National Institutes of Health (NIH) guidelines. For prostate regeneration experiments, all mice were on the $F V B$ genetic background. Ikk $\alpha^{A A}$ and TRAMP mice were intercrossed to create $I k k \alpha^{A A / A A} /$ TRAMP and $I k k \alpha^{+/ A A} /$ TRAMP littermates of nearly identical genetic background. subcutaneous myc$\mathrm{CaP}$ tumors were grown in $F V B$ mice. Human material was obtained from Cooperative Human Tissue Network (CHTN). Additional methods are available in the Supplemental Material.

\section{Acknowledgments}

We thank Y.X. Fu for the LT $\beta R$-Ig fusion protein, L. Coussens for ${J_{H}}^{-1-}$ and $C D 4^{-1-}$ mice, M.C. Hung for CBP vector, Genentech for anti-CD20, and eBioscience for FACS antibodies. M.A. was supported by AICF and Department of Defense Congressionally Directed Medical Research Programs. A.I.K. was supported by the American Cancer Society. S.S. was supported by the German Research Foundation (Deutsche Forschungsgemeinschaft, SH721/1-1). A.S. was supported by a Nation Cancer Institute grant (T32CA121938). W.Z. was supported by a NIH Pathway to Independence award (K99/R00 CA158055-01). Work was supported by an NIH grant (CA127923) to M.K., who is an American Cancer Society Research Professor and holder of the Hildyard Chair for Mitochondrial and Metabolic Diseases.

\section{References}

Ammirante M, Luo JL, Grivennikov S, Nedospasov S, Karin M. 2010. B-cell-derived lymphotoxin promotes castration-resistant prostate cancer. Nature 464: 302-305.

Beachy PA, Karhadkar SS, Berman DM. 2004. Tissue repair and stem cell renewal in carcinogenesis. Nature 432: 324-331.

Ben-Neriah Y, Karin M. 2011. Inflammation meets cancer, with NF-кB as the matchmaker. Nat Immunol 12: 715-723.

Cao Y, Bonizzi G, Seagroves TN, Greten FR, Johnson R, Schmidt EV, Karin M. 2001. IKK $\alpha$ provides an essential link between RANK signaling and cyclin D1 expression during mammary gland development. Cell 107: $763-775$.

Chen J, Trounstine M, Alt FW, Young F, Kurahara C, Loring JF, Huszar D. 1993. Immunoglobulin gene rearrangement in B cell deficient mice generated by targeted deletion of the JH locus. Int Immunol 5: 647-656.

Dvorak HF. 1986. Tumors: Wounds that do not heal. Similarities between tumor stroma generation and wound healing. $N$ Engl J Med 315: 1650-1659.

English HF, Santen RJ, Isaacs JT. 1987. Response of glandular versus basal rat ventral prostatic epithelial cells to androgen withdrawal and replacement. Prostate 11: 229-242.

Greenberg NM, DeMayo F, Finegold MJ, Medina D, Tilley WD, Aspinall JO, Cunha GR, Donjacour AA, Matusik RJ, Rosen JM. 1995. Prostate cancer in a transgenic mouse. Proc Natl Acad Sci 92: 3439-3443.

Gulley J, Figg WD, Dahut WL. 2003. Treatment options for androgenindependent prostate cancer. Clin Adv Hematol Oncol 1: 49-57.

Guo WJ, Datta S, Band V, Dimri GP. 2007. Mel-18, a polycomb group protein, regulates cell proliferation and senescence via transcriptional repression of Bmi-1 and c-Myc oncoproteins. Mol Biol Cell 18: 536-546.

Hoberg JE, Popko AE, Ramsey CS, Mayo MW. 2006. IкB kinase $\alpha$-mediated derepression of SMRT potentiates acetylation of RelA/p65 by p300. Mol Cell Biol 26: 457-471.

$\mathrm{Hu}$ Y, Baud V, Oga T, Kim KI, Yoshida K, Karin M. 2001. IKK $\alpha$ controls formation of the epidermis independently of NF-кB. Nature 410: 710714.

Huang WC, Ju TK, Hung MC, Chen CC. 2007. Phosphorylation of CBP by IKK $\alpha$ promotes cell growth by switching the binding preference of CBP from p53 to NF-кB. Mol Cell 26: 75-87.

Ianari A, Gallo R, Palma M, Alesse E, Gulino A. 2004. Specific role for p300/CREB-binding protein-associated factor activity in E2F1 stabilization in response to DNA damage. J Biol Chem 279: 30830-30835.
Ivanova IA, Nakrieko KA, Dagnino L. 2009. Phosphorylation by p38 MAP kinase is required for E2F1 degradation and keratinocyte differentiation. Oncogene 28: 52-62.

Iyer NG, Ozdag H, Caldas C. 2004. p300/CBP and cancer. Oncogene 23: 4225-4231.

Jacobs JJ, Scheijen B, Voncken JW, Kieboom K, Berns A, van Lohuizen M. 1999. Bmi-1 collaborates with c-Myc in tumorigenesis by inhibiting c-Myc-induced apoptosis via INK4a/ARF. Genes Dev 13: 2678-2690.

Karhadkar SS, Bova GS, Abdallah N, Dhara S, Gardner D, Maitra A, Isaacs JT, Berman DM, Beachy PA. 2004. Hedgehog signalling in prostate regeneration, neoplasia and metastasis. Nature 431: 707-712.

Karin M. 2009. NF-кB as a critical link between inflammation and cancer. Cold Spring Harb Perspect Biol 1: a000141.

Kasper S. 2008. Exploring the origins of the normal prostate and prostate cancer stem cell. Stem Cell Rev 4: 193-201.

Kuraishy A, Karin M, Grivennikov SI. 2011. Tumor promotion via injuryand death-induced inflammation. Immunity 35: 467-477.

Lawson DA, Xin L, Lukacs RU, Cheng D, Witte ON. 2007. Isolation and functional characterization of murine prostate stem cells. Proc Natl Acad Sci 104: 181-186.

Lukacs RU, Memarzadeh S, Wu H, Witte ON. 2010. Bmi-1 is a crucial regulator of prostate stem cell self-renewal and malignant transformation. Cell Stem Cell 7: 682-693.

Luo JL, Tan W, Ricono JM, Korchynskyi O, Zhang M, Gonias SL, Cheresh DA, Karin M. 2007. Nuclear cytokine-activated IKK $\alpha$ controls prostate cancer metastasis by repressing Maspin. Nature 446: 690-694.

Maitland NJ, Collins AT. 2008. Prostate cancer stem cells: A new target for therapy. J Clin Oncol 26: 2862-2870.

Ohtani K, DeGregori J, Nevins JR. 1995. Regulation of the cyclin E gene by transcription factor E2F1. Proc Natl Acad Sci 92: 12146-12150.

Rahemtulla A, Fung-Leung WP, Schilham MW, Kundig TM, Sambhara SR, Narendran A, Arabian A, Wakeham A, Paige CJ, Zinkernagel RM, et al. 1991. Normal development and function of $\mathrm{CD}^{+}$cells but markedly decreased helper cell activity in mice lacking CD4. Nature 353: $180-184$

Siegel R, Naishadham D, Jemal A. 2012. Cancer statistics, 2012. CA Cancer J Clin 62: 10-29.

Sil AK, Maeda S, Sano Y, Roop DR, Karin M. 2004. IкB kinase- $\alpha$ acts in the epidermis to control skeletal and craniofacial morphogenesis. Nature 428: 660-664.

Trouche D, Kouzarides T. 1996. E2F1 and E1A(12S) have a homologous activation domain regulated by RB and CBP. Proc Natl Acad Sci 93: 1439-1442.

Tu Z, Prajapati S, Park KJ, Kelly NJ, Yamamoto Y, Gaynor RB. 2006. IKK $\alpha$ regulates estrogen-induced cell cycle progression by modulating E2F1 expression. I Biol Chem 281: 6699-6706.

Velnar T, Bailey T, Smrkolj V. 2009. The wound healing process: An overview of the cellular and molecular mechanisms. J Int Med Res 37: $1528-1542$.

Wang H, Wang L, Erdjument-Bromage H, Vidal M, Tempst P, Jones RS, Zhang Y. 2004. Role of histone H2A ubiquitination in Polycomb silencing. Nature 431: 873-878.

Yamamoto Y, Verma UN, Prajapati S, Kwak YT, Gaynor RB. 2003. Histone $\mathrm{H} 3$ phosphorylation by IKK- $\alpha$ is critical for cytokine-induced gene expression. Nature 423: 655-659.

Zitvogel L, Kepp O, Kroemer G. 2010. Decoding cell death signals in inflammation and immunity. Cell 140: 798-804. 


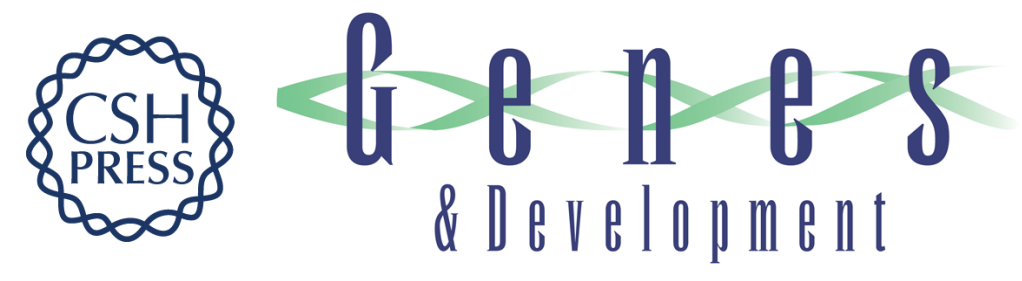

\section{An IKK $\alpha-E 2 F 1-B M I 1$ cascade activated by infiltrating B cells controls prostate regeneration and tumor recurrence}

Massimo Ammirante, Ali I. Kuraishy, Shabnam Shalapour, et al.

Genes Dev. 2013, 27: originally published online June 24, 2013

Access the most recent version at doi:10.1101/gad.220202.113

\section{Supplemental http://genesdev.cshlp.org/content/suppl/2013/06/17/gad.220202.113.DC1 Material}

References This article cites 35 articles, 11 of which can be accessed free at: http://genesdev.cshlp.org/content/27/13/1435.full.html\#ref-list-1

License Freely available online through the Genes \& Development Open Access option. Email Alerting
Service $\begin{aligned} & \text { Receive free email alerts when new articles cite this article - sign up in the box at the top } \\ & \text { right corner of the article or click here. }\end{aligned}$

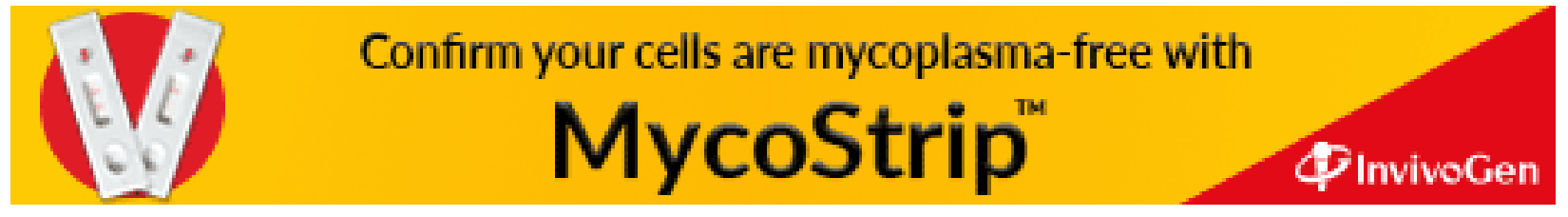

